www.pasosonline.org

\title{
Turismo de sol e mar e a territorialização do destino Maceió, Brasil
}

\author{
Daniel Arthur Lisboa de Vasconcelos* \\ Lindemberg Medeiros de Araujo** Silvana Pirillo Ramos***
}

Universidade Federal de Alagoas (Brasil)

\begin{abstract}
Resumo: O trabalho examina a territorialização do turismo no destino Maceió, Estado de Alagoas, Brasil. Delineia-se a produção histórica e espacial desse destino, analisando-se as territorializações que se consolidaram como resultado do modelo dominante de desenvolvimento turístico local, com ênfase em período recente. Adotou-se uma abordagem qualitativa, com análise documental e entrevistas semiestruturadas com informantes relacionados ao governo e ao trade turístico, e outros ligados ao turismo nessa destinação. Constatou-se a necessidade de se repensar a sustentação territorial deste destino, com base em mobilização dos seus recursos físicos, naturais, ambientais, sociais e culturais, e não apenas em atrativos massificados de sol e mar. Seria importante ainda: valorizar elementos culturais singulares; diversificar a oferta; e inserir elementos culturais identitários para fortalecer a imagem do destino.
\end{abstract}

Palavras-chave: Turismo; Território; Destino; Maceió; Brasil.

Sun and sea tourism and the territorialization of the destination Maceió, Brazil

Abstract: This study examines tourism territorialization in the destination Maceió, Brazil. To this aim, the historic production of the space of the destination Maceió is outlined and an analysis is conducted of the territorializations that have materialized as a result of the prevailing model of local tourism development, with an emphasis on recent years. A qualitative approach was adopted, with analysis of documents and semi-structured interviews with key individuals of the government, tourism trade, and others. Results identify serious constraints to an effective consolidation of the destination Maceió. The study identifies the need to rethink the sustainability of this destination based on the mobilization of its rich physical, natural, environmental, social and cultural resources, and not only based on the destination's natural resources. It would also be important to: value unique local cultural elements; diversify supply; and insert cultural identity elements to strengthen the image of destination.

Keywords: Tourism; Territory; Destination; Maceió; Brazil.

\section{Introdução}

A dinâmica territorial das atividades humanas é governada pela confluência de interesses de diferentes agentes sociais que deixam marcas no tempo e no espaço (Harvey, 1989), constituindo fatores intrínsecos aos processos de territorialização, tanto de cunho material quanto em relação a sua representação simbólica (Haesbaert, 2004; 2012). A influência de interesses na determinação das configurações territoriais constitui um fenômeno comum a todas as atividades socioeconômicas como, por exemplo, agricultura, extrativismo, mineração e comércio, tanto em países desenvolvidos quanto naqueles em desenvolvimento, incluindo os setores primário, secundário e terciário da economia. Assim, essa asserção se aplica igualmente ao turismo, uma atividade que nas últimas décadas organizou e

\footnotetext{
* Universidade Federal de Alagoas (Brasil); E-mail: daniel_tur@hotmail.com

** Universidade Federal de Alagoas (Brasil); E-mail: lmedeirosbr@gmail.com

*** Universidade Federal de Alagoas (Brasil); E-mail: silvanapirillo@uol.com.br
} 
reorganizou territórios em vastas áreas do planeta, principalmente em regiões litorâneas, causando mudanças econômicas, sociais, culturais, políticas e ambientais. Por isso, é necessário se pensar como se dão as relações entre os processos de territorialização e a espacialização do turismo, adotando como premissa fundamental que não há atividade humana que não interfira no espaço e nos processos de territorialização.

O turismo é um fenômeno multifacetado que envolve uma ampla cadeia produtiva. Por isso, a apropriação do espaço por ele realizada inclui aspectos materiais, a exemplo da infraestrutura urbana básica e aquela voltada diretamente ao uso turístico, como a rede de hospedagem e os receptivos (Rodrigues, 1997, 1997a). Os aspectos imateriais, de natureza cultural e simbólica, também são apropriados pelo e para uso turístico, tornando-se não somente parte dos atrativos dos destinos, mas também constituindo elementos que influenciam a própria produção do espaço. Além disso, o turismo envolve interfaces com diversas outras dimensões da realidade, a exemplo da econômica, da social da ambiental e da esfera política, o que aumenta seu potencial de configurar e reconfigurar territórios (Rodrigues, 1997, 1997a; Cruz, 2000; 2001), influenciando na formação espacial dos destinos. Sob essa perspectiva é que opera um processo espacial de territorialização impulsionado pelo turismo denominado turistificação.

Este trabalho aborda como se deu a territorialização do destino Maceió, capital do Estado de Alagoas, com ênfase no período recente. Esse destino localiza-se no litoral da região Nordeste do Brasil (Figura 1). Esta cidade conta com uma população de aproximadamente 1 milhão de habitantes (IBGE, 2018), tendo recebido cerca de 1,7 milhões de visitantes em 2016 (Alagoas, s.d.). Esse destino teve seu desenvolvimento turístico fomentado a partir da década de 1970, quando o governo estadual constatou o potencial local para o histórico-cultural em Maceió. A turistificação desse destino está ancorada em uma oferta excessivamente centrada em atrativos de sol e mar, de modo semelhante ao que ocorre em incontáveis outros destinos de massa ao redor do mundo. $\mathrm{O}$ estudo buscou responder a duas questões inter-relacionadas: 1. Como a territorialização do turismo de massa, sob o segmento de sol e mar, influenciou a formação espacial do destino Maceió? 2. Quais agentes influenciaram mais a evolução do destino Maceió, com ênfase no período recente? O trabalho tem como objetivo geral compreender como se deu a evolução recente do destino Maceió, identificando os principais fatores intervenientes, com ênfase no papel desempenhado nos pelos agentes envolvidos.

A pesquisa empregou uma abordagem qualitativa, que envolveu a coleta de dados por meio de pesquisa documental (relatórios e dados estatísticos da Secretaria de Turismo do Estado de Alagoas - Setur, legislação e atas de reuniões), observação de campo, e entrevistas semiestruturadas com 18 (dezoito) indivíduos, compostos por representantes do trade turístico, agentes públicos ligados ao fomento do turismo no destino, e pesquisadores. As entrevistas, que tiveram o livre consentimento dos entrevistados, foram gravadas e transcritas e posteriormente submetidas a análise discursiva.

\section{Marco Teórico: espaço, turistificação e território em destinos turísticos}

O turismo é uma prática social que envolve o deslocamento de pessoas (Urry, 1990) e que tem como seu objeto de consumo o espaço (Rodrigues, 1997, 1999; Cruz, 2000, 2001). Dessa forma, a atividade turística interfere na dinâmica espaço-territorial dos lugares e produz um processo denominado turistificação (Rodrigues, 2015; Fratucci, 2008; Knafou, 2001, 2001). Fratucci (2008) afirma que esse termo tem sido utilizado nos estudos do turismo para

[...] designar o processo de apropriação de trechos do espaço pelos agentes do turismo para a implantação da atividade turística, pela inclusão de novos fixos e/ou da refuncionalização de outros já existentes e de novos fluxos e relações que caracterizam o turismo como fenômeno socioespacial contemporâneo (Fratucci, 2008, p. 66).

A turistificação do espaço gera consequências materiais e simbólicas. Ela está intimamente ligada aos processos de expansão da atividade turística em diversas escalas. Para este trabalho compreendemos a turistificação como um processo espacial de territorialização pelo e para o turismo, assentado em uma lógica de produção do espaço que tem por finalidade produzir e reproduzir a atividade turística, com base em uma relação entre o turismo e diversas outras atividades socioeconômicas que formam o espaço geográfico. Entendemos que o turismo é um fenômeno consumidor e produtor de espaço, portanto uma atividade territorializadora, mas que depende de outras atividades socioeconômicas presentes nos lugares turísticos para se realizar. 
Os conceitos de espaço e território podem contribuir para avanços na compreensão de como a turistificação ocorre e sobre suas implicações para os destinos. Nesse sentido, Lefebvre (1992), Santos (2008) e Harvey (1989), não obstante diferenças conceituais nas suas respectivas produções teóricas, entendem o espaço como produto das relações da sociedade com a natureza. Por isso, a contribuição teórica desses autores permite uma compreensão do espaço que não se restringe à descrição dos seus componentes materiais. Consideremos, então, que o espaço como categoria analítica constitui um ente que é, simultaneamente, produto e produtor da ação humana, uma noção que está alinhada com o pensamento de Santos (2008), para quem

[...] o espaço [é] uma instância da sociedade, ao mesmo título que a instância econômica e a cultural-ideológica. Isso significa que, como instância, ele contém e é contido pelas demais instâncias, assim como cada uma delas o contém e é por ele contida. A economia está no espaço, assim como o espaço está na economia. O mesmo se dá com o político-institucional e com o cultural-ideológico. Isso quer dizer que a essência do espaço é social (2008, p. 12).

De maneira semelhante, Harvey (1989) propõe que o espaço geográfico também é construído historicamente pelo ser social. Harvey analisa a relação entre o espaço e o tempo histórico, buscando identificar fatores multidimensionais intervenientes (econômicos, políticos, culturais, etc.), afirmando que o espaço é relacional. Ele também explora o modo pelo qual representamos o espaço e o tempo, argumentando que os fluxos espaciais estão contidos no espaço produzido, enfatizando, com esse argumento, uma concepção simbólica e identitária do espaço, conceito herdado de Lefebvre (1992).

Já o conceito de território é compreendido, neste trabalho, como resultado da apropriação e ocupação do espaço geográfico por grupos sociais, o que gera identificações socioespaciais, de cunho material e simbólico. Conforme Haesbaert (2004), a etimologia do termo território surge com uma dupla conotação: material, terra/territorium e simbólica, terrio/territor (terror, aterrorizar). Esse autor explica que essas raízes etimológicas têm relação respectivamente com os significados de dominação jurídico- política da terra e com a imposição do medo para aqueles que ficam impedidos de adentrar a essa "terra" ou território. Entende-se também que os privilegiados pelo usufruto do território apropriam-se efetivamente e identificam-se com os territórios que se encontram sob o seu domínio. Em qualquer desses significados o conceito de poder insere-se, seja ele no seu sentido concreto (de dominação) ou no seu sentido simbólico (de apropriação) (Haesbaert, 2012). Para Raffestin (1993), o território é uma construção conceitual a partir da noção de espaço, ao argumentar que o espaço geográfico é uma base que antecede a formação de um território, sendo resultante das ações sociais pelas quais os indivíduos e grupos sociais se apropriam de porções espaciais de forma concreta ou abstrata, territorializando-as. Em última instância, o território é um campo de forças e de relações de poder que são espacialmente delimitadas e que operam sobre um substrato de referência.

Neste trabalho, consideramos a turistificação como um processo espacial de territorialização pelo e para o turismo, assentado na produção espacial e que tem por finalidade a produção e a reprodução da atividade turística e dos interesses envolvidos, do ponto de vista material e simbólico. Nesse sentido, partimos do princípio de que não há espaço turístico per se, e sim espaço geográfico territorializado pelo turismo, por meio de um processo de turistificação. Do contrário, haveria o risco de um reducionismo estéril que ignoraria as relações do turismo com as dimensões físico-naturais, econômicas, sociais, culturais e políticas, sem as quais o turismo não existiria.

É nesse contexto que são produzidos os destinos, enquanto territórios turísticos. Na síntese conceitual de Haugland et al. (2011), para autores como Gunn (1994), Pearce (1989), Hu e Brent Ritchie (1993), Buhalis (2000), e Murphy, Pritchard e Smith (2000), os destinos turísticos podem ser considerados como redes complexas que envolvem um grande número de agentes, sendo estes coprodutores, capazes de oferecer uma variedade de produtos e serviços. Nesse sentido, enquanto os visitantes podem perceber o destino como uma unidade capaz de ofertar uma experiência integrada, ou um produto (Buhalis, 2000; Murphy; Pritchard; Smith (apud Haugland et al., 2011), esta experiência, ou produto, ainda continua sendo produzida e composta por esses atores (Haugland et al., 2011). É no destino que se encontram reunidos os aspectos mais centrais do turismo, quais sejam: a demanda turística, os transportes, os suprimentos e o mercado. O destino e as imagens por ele geradas atraem os turistas e movimentam o sistema de turismo (Haugland et al., 2011), valorizando certos recursos e interesses e, ao mesmo tempo, marginalizando outros.

De forma semelhante, González Reverté e Antón Clavé (2007) consideram que o destino turístico pode ser analisado como um sistema territorial, o qual teria características específicas, no que se refere 
à sua finalidade social, isto é, a gestão das expectativas dos turistas. Suas características específicas também estão condicionadas por fatores como a legislação vigente, a tecnologia disponível localmente e os agentes intervenientes em seu desenvolvimento. Conforme Knafou (2001), os agentes do mercado turístico e os promotores territoriais dessa atividade, ao escolherem, delimitarem, criarem e inventarem os lugares para o turismo, têm um grande poder de influência sobre a configuração e reconfiguração dos destinos. Esses promotores do turismo canalizam ações de marketing e de produção do território turístico, seja diretamente no interior das cidades ou indiretamente nas áreas sob a sua influência.

Com suporte na discussão teórica anterior, e com o objetivo de contribuir com o avanço na teorização desse conceito, propomos a seguinte concepção espacial de destino turístico: se trata de uma porção do espaço geográfico, turistificada ou territorializada pelo turismo, que abrange territórios pré-existentes, assim como a contribuição do próprio turismo frente à formação da configuração territorial de uma região ou localidade.

Um destino turístico, assim como o território que é resultante da turistificação, apresenta limites mais ou menos flexíveis, respondendo ao movimento dos próprios turistas, do mercado e do governo, a partir de uma referência espacial central, normalmente uma cidade. Ao mesmo tempo, o espaço geográfico e os territórios precedentes, que se estendem por uma área que excede em graus variáveis os limites do destino, são basilares para a formação do próprio destino, uma vez que oferecem suporte físico, biológico, econômico, social e cultural que servem de recursos para a composição da própria oferta turística local e regional, conferindo uma identidade particular ao destino. Dito de outra forma: quando o turismo se materializa sobre uma base espaço-territorial preexistente, os agentes que comandam o funcionamento do destino mobilizam os elementos de interesse para o turismo e dinamizam o território, recebem influências dele (do território) e, dialeticamente, influenciam a sua dinâmica, um fenômeno que pode ser demonstrado empiricamente pelo processo de territorialização do destino Maceió, que tem sua localização situada na figura 1.

\section{Figura 1: Mapa de localização do destino Maceió}

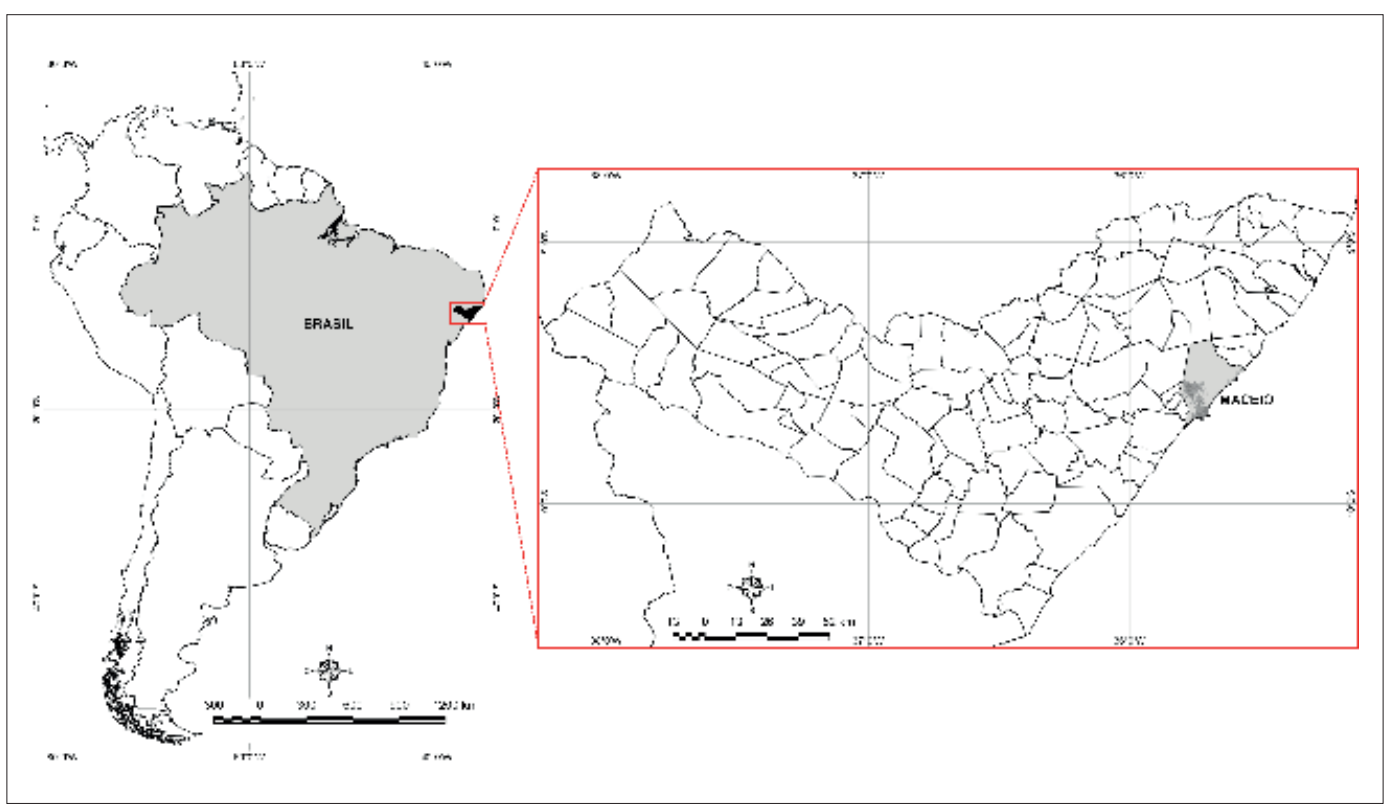

Fonte: elaborado pelos autores.

\section{Estudo de Caso}

\subsection{O destino Maceió: breve retrospecto histórico-espacial}

O desenvolvimento do destino turístico Maceió, desde os seus primórdios teve por base atratividades de sol e mar, resultado da sua natureza de cidade litorânea com características fisiográficas muito 
atrativas e das escolhas feitas pelos promotores do destino. Segundo Veras Filho (1991), o turismo teve início em Maceió nas últimas décadas do século XIX. Até meados do século XX, a influência de um turismo ainda incipiente na urbanização da cidade foi limitada, tanto pela relativa pequena expressão numérica de visitantes quanto pela existência apenas de hotéis de pequeno porte e com características tradicionais. Para Veras Filho (1991), Costa (1998) e Rangel (2010) a década de 1970 representa os primórdios da expansão turística em Maceió nos moldes contemporâneos, com importantes melhorias na sua infraestrutura básica e nos equipamentos turísticos.

Assim, a década de 1970 presenciou uma etapa de crescimento e modernização do turismo em Maceió. A cidade cresceu, a orla do bairro de Pajuçara foi urbanizada (em 1974) e foi aberta a avenida que atualmente liga o bairro de Ponta Verde à chamada Lagoa da Anta, atualmente denominada Avenida Álvaro Otacílio. A partir dessas transformações urbanas, foram inaugurados restaurantes e hotéis de grande porte nessa parte da cidade. Com isso, o trecho de orla formado pelos bairros de Pajuçara, Ponta Verde e Jatiúca se tornou a área central da urbanização turística e das atividades de lazer da cidade.

Em estudo sobre o ciclo de vida do destino Maceió, com base no modelo TALC - Tourist Area Life Cycle, de Butler (1980), Rangel (2010) identificou as fases do ciclo de vida desse destino, até o ano de publicação do seu estudo (2010). O modelo de Butler (1980) distingue cinco fases evolutivas de um lugar turístico, a saber: Exploração, Envolvimento, Desenvolvimento, Consolidação e Estagnação. Rangel (2010) situa temporalmente as seguintes fases do ciclo de vida do destino Maceió (Quadro 1): Antecedentes (1937-1978), Desenvolvimento (1979-1985), Consolidação (1986-1988), Estagnação (1989-1996) e Pós-estagnação (a partir de 1997). Diante da inexistência de dados para caracterizar as fases Exploração e Envolvimento, Rangel (2010) denominou o tempo anterior à fase Desenvolvimento de "Antecedentes" e analisou o ciclo de vida desse destino a partir da fase Desenvolvimento.

Para Rangel (2010), apesar de a literatura identificar atividades turísticas na cidade de Maceió e no Estado de Alagoas já na década de 1930, como mencionado por Brandão (1937), no seu livro "Vade-Mecuum do turista em Alagoas", tais atividades eram incipientes e esparsas. Em seu estudo, Rangel (2010) identifica a inauguração do Hotel Jatiúca, em 1979, como o evento que precipitou o início do estágio "desenvolvimento" (Butler, 1980) do destino Maceió, marcado desde aquele ano pela venda de um produto que tinha como base uma oferta de sol e mar, e que se estendeu até o presente, com indicativos atuais de continuação nos anos seguintes.

Com avanços na sua infraestrutura turística, Maceió experimentou rápido crescimento na sua demanda turística, com a beleza cênica da cidade e a natureza, particularmente as praias, funcionando como os grandes fatores de atração (Costa, 1998). Entre 1980 e 1990, o Estado de Alagoas, cuja maior parte do fluxo se concentra em Maceió, chegou a ser um dos destinos turísticos mais visitados da região Nordeste do Brasil. Contudo, após passar por uma fase de estagnação houve um acentuado declínio na demanda turística do destino, devido a problemas político-institucionais locais e instabilidades econômicas no país (Costa, 1998). Na primeira metade da década de 1990, conforme dados da Comissão de Turismo Integrada do Nordeste - CTI/NE, o destino Maceió chegou a ocupar as últimas posições na preferência dos turistas que visitaram a região Nordeste do país naquele período (Martins, 2009). Tal fato desencadeou o início de uma fase de estagnação do destino. Fatores de ordem econômica, política, e ambiental, atuando juntos naquele período histórico, funcionaram como uma barreira que limitou temporariamente a continuidade do crescimento do destino, até aproximadamente 1996, com o ano de 1997 marcando o início de um processo de rejuvenescimento.

\subsection{Pós-estagnação - rejuvenescimento do destino Maceió}

O modelo de Butler (1980) prevê que quando um lugar turístico (destino) atinge uma fase de estagnação ele passará por um dos seguintes cenários: Declínio, Estabilização ou Rejuvenescimento. O destino Maceió passou por uma fase de estagnação, que se iniciou em 1989 e terminou em 1996, com o ano de 1997 marcando o início de um processo de rejuvenescimento (Figura 2). Se o destino chegou à estagnação com base em uma oferta de sol e mar, foi também com esse tipo de oferta que o rejuvenescimento ocorreu (Alagoas, s.d.), consolidando a oferta turística de sol e mar como força motriz principal do destino Maceió. Por exemplo, entre 1998 e 2006, 53,09\% dos visitantes do destino Maceió veio a passeio e em média 93,58\% deles informou que os atrativos naturais foram o principal fator influenciador da escolha do destino, motivo citado também por $98,33 \%$ dos turistas que visitaram o destino em 2003 (Vasconcelos, 2005). 
Quadro 1: Fases do ciclo de vida do destino Maceió.

\begin{tabular}{|c|c|l|}
\hline Fase & Período & \multicolumn{1}{|c|}{ Fatos marcantes no período } \\
\hline Antecedentes & $\ldots-1978$ & $\begin{array}{l}\text { Período dos primórdios do contato dos turistas com destino } \\
\text { Maceió. } \\
\text { Esse momento abarca os fatos anteriores à inauguração do } \\
\text { Hotel Jatiúca, importante marco para o turismo de Maceió. }\end{array}$ \\
\hline Desenvolvimento & $1979-1985$ & $\begin{array}{l}\text { Inauguração do Hotel Jatiúca. } \\
\text { Início da divulgação do destino. } \\
\text { Aumento da demanda turística. }\end{array}$ \\
\hline Consolidação & $1986-1988$ & $\begin{array}{l}\text { Divulgação do destino e crescimento da hotelaria. } \\
\text { Aumento acentuado da demanda turística. } \\
\text { Maceió se consolidou como destino turístico de sol e mar. }\end{array}$ \\
\hline Estagnação & $1989-1996$ & $\begin{array}{l}\text { O destino Maceió entra em relativa estagnação de demanda } \\
\text { turística. } \\
\text { Problemas políticos do estado e do município. } \\
\text { Problemas ambientais (lixo na cidade, praias poluídas, etc.). }\end{array}$ \\
\hline $\begin{array}{c}\text { Pós-Estagnação } \\
\text { (Rejuvenescimento) }\end{array}$ & $1997-\ldots$ & $\begin{array}{l}\text { Retomada de crescimento na demanda de turistas. } \\
\text { Crescimento na oferta hoteleira em Maceió e outros } \\
\text { municípios de Alagoas. } \\
\text { Incrementos na gestão pública e privada do destino Maceió } \\
\text { e do destino Alagoas. }\end{array}$ \\
\hline
\end{tabular}

Fonte: elaboração dos autores com base em Rangel (2010).

Figura 2: Representação evolutiva do fluxo global de visitantes em Maceió (1997 a 2015) - número de visitantes/ano

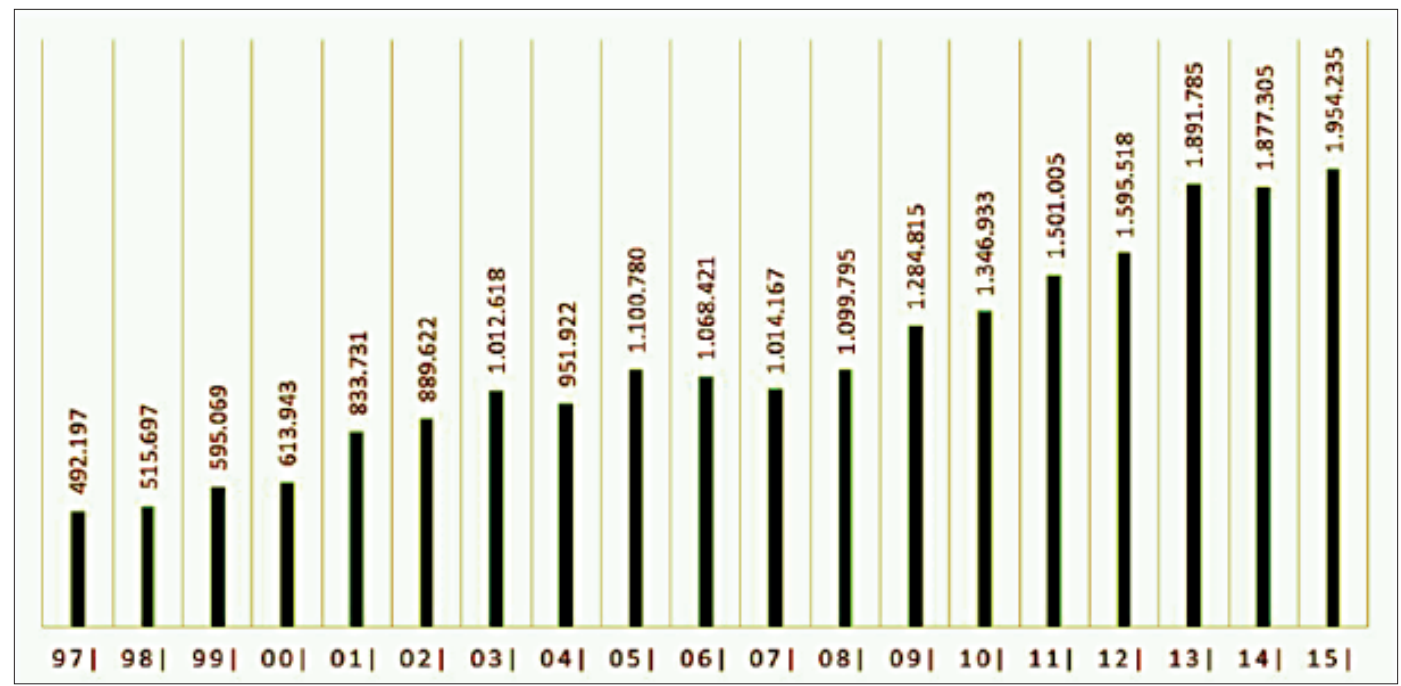

Fonte: elaboração dos autores, com base em Alagoas (s.d.).

Além de depender quase que exclusivamente de uma oferta de sol e mar, o destino Maceió é afetado por uma marcada sazonalidade climática, havendo uma baixa acentuada na demanda turística nos meses chuvosos, ou seja, de março a agosto. Por isso, os promotores do destino buscaram diversificar a oferta turística de Maceió para enfrentar a baixa temporada, tentando desenvolver atrativos ligados ao patrimônio histórico-cultural. A principal tentativa de diversificação foi um conjunto de ações voltadas à revitalização do histórico bairro portuário de Jaraguá, bairro esse que é considerado como 
um dos principais centros irradiadores da formação urbana da cidade de Maceió. Essa tentativa foi financiada com recursos do Programa para o Desenvolvimento do Turismo no Nordeste - Prodetur/ NE, e foi implantada nos últimos anos da década de 1990 e início dos anos 2000 (Vasconcelos, 2005). Entretanto, essa estratégia teve apenas resultados temporários, pois depois de experimentar intensa visitação turística e de residentes durante os primeiros anos das ações de revitalização, por volta de 2003 o bairro já havia perdido quase todo o impulso atrativo pós-revitalização, voltando a ser um lugar relativamente à margem dos fluxos turísticos da cidade até o presente.

Em anos subsequentes, dois outros importantes projetos foram implantados com o objetivo de oferecer melhores condições para a expansão do destino e, até certo ponto, fomentar a diversificação da oferta turística local. O primeiro projeto, inaugurado em 2005, foi o Centro Cultural e de Exposições de Maceió. Conforme Martins (2009), até aquele ano, Maceió era a única capital do Nordeste brasileiro que não contava com um equipamento prioritariamente destinado à realização de convenções. Para esse autor, a construção desse equipamento fomentou outros segmentos de turismo, com destaque para o segmento de eventos. O segundo projeto foi a construção do novo Aeroporto Internacional Zumbi dos Palmares, também inaugurado em 2005. O novo aeroporto capacitou Maceió e Alagoas a receberem voos internacionais, influenciando o crescimento do turismo em Maceió e outros lugares que compõem esse destino, a exemplo da Praia do Francês, Barra de São Miguel e litoral norte do município de Maceió. Segundo dados oficiais (Alagoas, s.d.), no ano de 2005 o destino Maceió recebeu 1.100 .780 visitantes, superando a marca de 951.922 visitantes registrada no ano anterior.

$\mathrm{Na}$ segunda metade da década de 2000, os bairros de Pajuçara, Ponta Verde e Jatiúca (Figura 3) passaram por um processo de adensamento populacional e valorização fundiária (Martins; Lima, 2007). Como consequência e também impulsionado pelo aumento da demanda turística, registrou-se um crescente aumento na verticalização das construções nesses bairros, com edificações destinadas aos grupos sociais de renda alta e média, além de maciça concentração de imóveis comerciais e de serviços gerais, como galerias, clínicas médicas, assim como aqueles mais diretamente ligados ao lazer, como bares e restaurantes, além de diversos tipos de meios de hospedagem, desde os mais simples, como albergues e pousadas, até hotéis que estão incluídos entre os mais sofisticados da cidade. Representantes do governo estadual e municipal entrevistados para este trabalho identificaram a valorização desse trecho da cidade pelo turismo. Ao questionarmos sobre qual ou quais seriam os pontos fortes do destino Maceió, a maioria dos entrevistados deu centralidade à orla dos bairros de Pajuçara, Ponta Verde e Jatiúca como o espaço mais favorável e valorizado para o turismo nesse destino.

Os investimentos em urbanização feitos nesse trecho turístico da capital alagoana, o aumento do fluxo de visitantes e o crescimento econômico da atividade turística, levaram grupos nacionais, internacionais e locais a investir mais em infraestrutura hoteleira. Como consequência, no ano de 2013 existiam 116 empreendimentos hoteleiros em Maceió, que ofereciam 6.280 unidades habitacionais, somando um total de 16.076 leitos, a maioria localizada justamente nos bairros de Pajuçara, Ponta Verde e Jatiúca (Alagoas, s.d.). Além disso, na última década ocorreram importantes intervenções espaço-territoriais em Maceió que deram sustentação ao seu processo de rejuvenescimento. Por exemplo, foi implantado um projeto de requalificação urbana em Maceió, no período 2007-2009, quando o poder público municipal promoveu obras de reestruturação da orla dos três bairros mencionados acima. Essas intervenções consolidaram, ainda mais, esse trecho litorâneo como o principal corredor de turismo e de lazer da cidade.

Logo após à consolidação dessa parte da orla como referência do turismo de sol e mar em Maceió, no ano de 2010 surgem notícias sobre uma possível continuação da revitalização dessa área da cidade, dessa vez contemplando o trecho litorâneo dos bairros de Cruz das Almas e Jacarecica, com uma extensão de aproximadamente três quilômetros. Com as obras iniciadas em 2014, custeadas por investimentos feitos por uma parceria firmada entre a Prefeitura de Maceió e o Ministério do Turismo (MTur), o projeto foi concluído em 2015. A revitalização desse novo trecho da orla de Maceió parece confirmar a existência de um processo de valorização do litoral norte do município de Maceió. No sentido norte, seguem-se os bairros de Guaxuma, Garça Torta, Riacho Doce, Pescaria e Ipióca, somando esses cinco bairros aproximadamente $19 \mathrm{~km}$ de um litoral que é contemplado com alto potencial paisagístico natural, composto de praias, rios, coqueirais, remanescentes de Mata Atlântica e manguezais. Essa parte do litoral de Maceió já possui diversas pousadas, hotéis e resorts. Não sem razão, essa parte da cidade vem sendo alvo de um visível processo de especulação imobiliária, relacionada não apenas ao turismo e ao veraneio, mas igualmente à função residencial. 
Figura 3: Destino turístico Maceió e seus lugares.

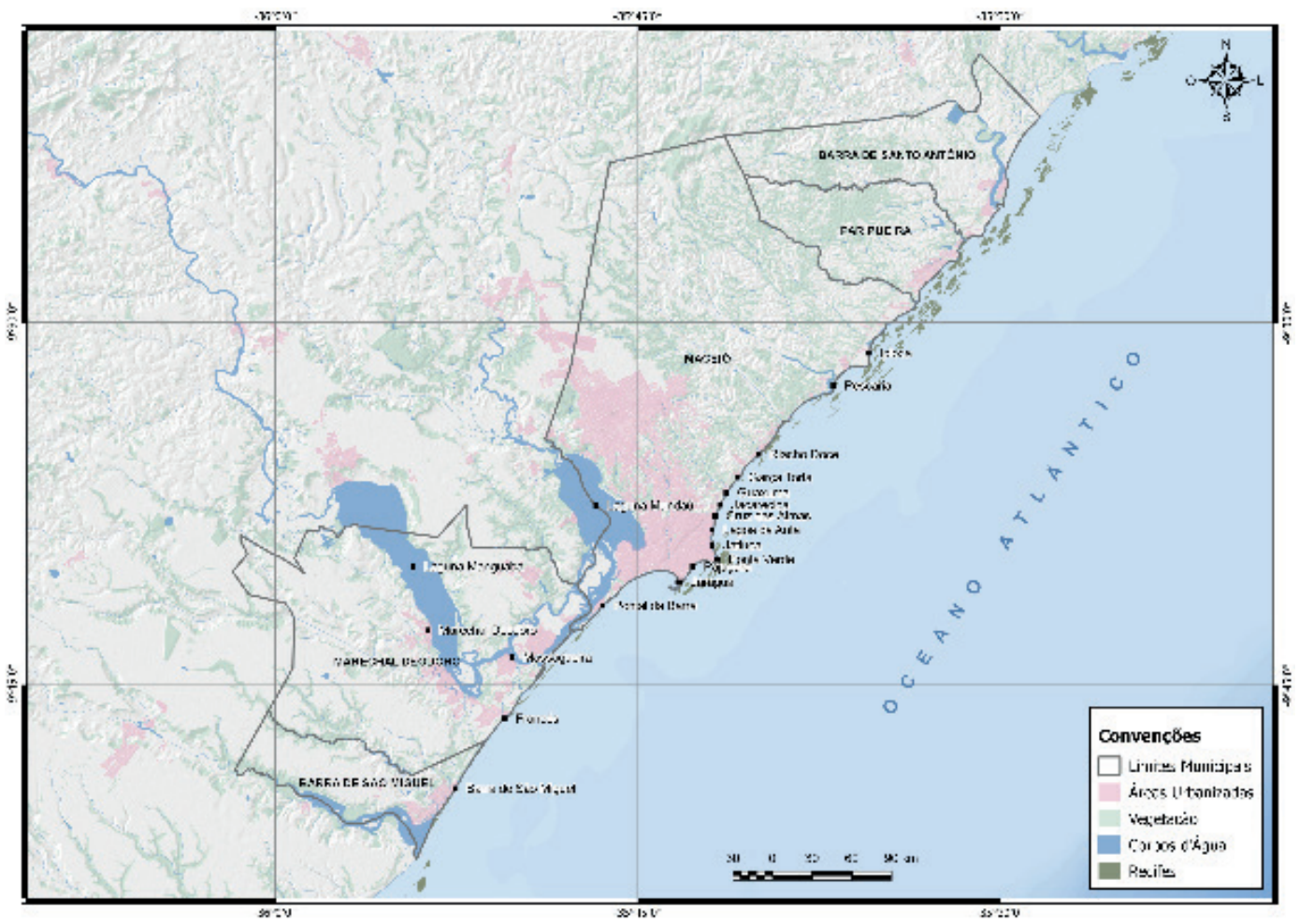

Fonte: elaboração dos autores.

Grupos ligados ao setor imobiliário conseguiram sucesso ao pressionarem o poder público no sentido de flexibilizar a legislação edilícia que incide sobre essa parte de Maceió (KRELL, 2008), sem o que muitas das intervenções imobiliárias recentes não teriam sido possíveis. Como resultado dessa mudança nos marcos legais do uso do solo, o bairro de Guaxuma está passando pelo início de um processo de verticalização, com a construção de prédios altos localizados próximos à praia.

\subsection{Territorialidades da turistificação de Maceió em período recente}

$\mathrm{Na}$ opinião de alguns dos entrevistados para este trabalho, os investimentos feitos em infraestrutura urbana e o alinhamento do trade turístico local com o poder público em anos recentes geraram bons resultados para o turismo em Maceió, o que contribuiu para um crescimento sustentado da demanda turística do destino de 1997 a 2015, tendência que continua no presente. De 1997 a 2015 o Maceió experimentou um rejuvenescimento, quando a demanda turística do destino quase quadruplicou em um período de apenas 18 anos. Verifica-se nesse rejuvenescimento a prevalência de interesses específicos influenciando as decisões sobre o sentido espacial da turistificação em Maceió, com o alinhamento dos interesses do trade turístico com os promotores públicos do turismo. Como prevê Harvey (1989), a confluência de determinados interesses governa a territorialização das atividades humanas. Areiterada eleição da orla marítima de Maceió como lócus dos investimentos em infraestrutura para atrair o turismo parece refletir a proposição de Haesbaert (2012) de que as representações simbólicas, neste caso, o imaginário do turismo de sol e mar, também têm influenciado a produção do território turístico no destino Maceió.

Outro aspecto importante da territorialização do turismo em Maceió é que suas influências se estendem a outros municípios do litoral alagoano, caracterizando uma capacidade de indução do desenvolvimento turístico a partir da capital para seu espaço circundante, tanto no sentido norte quanto em direção ao sul. Mais uma vez, essa situação parece refletir material e simbolicamente (Haesbaert, 2012) o território 
turístico litorâneo predominante em Alagoas que, em termos mercadológicos, é vendido e divulgado turisticamente como "destino Maceió". Essa influência territorial a partir de Maceió também tem suporte na rede de facilidades infra e superestruturais do núcleo irradiador de turismo receptivo, ou como denominam os técnicos de turismo entrevistados, a influência do "portão de entrada" Maceió, que serve como foco de irradiação dos fluxos turísticos para as áreas influenciadas por esse núcleo. Nesse caso, se refletem as influências do governo aliadas à iniciativa privada, nas decisões que determinam a territorialização do destino Maceió. Não por acaso, ao mesmo tempo fica clara a ausência de participação nas decisões de representantes de interesses não dominantes (para além daqueles da iniciativa privada e dos promotores territoriais ligados ao governo), o que relega os interesses dos grupos que representam o patrimônio histórico-cultural tradicional (artesãos, artistas, produtores culturais etc.) a segundo plano, o que tem impedido historicamente a emergência de uma diversificação na oferta turística no destino Maceió.

As falas seguintes dos entrevistados dão suporte a essa interpretação, pois denotam como a formatação da oferta do destino Maceió se orienta pelos interesses do turismo de massa de sol e mar:

Há dois produtos turísticos [...] que são vendidos no mercado: o vendido pelo setor político-institucional, e tem espaço geográfico nos limites do município de Maceió; e o vendido pelo setor privado. Neste último, o produto turístico Maceió [...] é apresentado como tendo espaço geográfico todo território de Alagoas, principalmente a zona litorânea.

Então, sobre esse aspecto, não dá pra desconsiderar (sic) o turismo em Maceió sem considerar as suas extensões nos dois litorais, principalmente [...] a região que vai até Barra de Santo Antônio até Barra de São Miguel, na verdade faz parte aí, do turismo de Alagoas. É uma coisa que é assim indivisível [...] mas agora sim estendendo [...] vai também um pouco até [...] Piaçabuçu, né, do Rio São Francisco, e é também por conta do passeio que você vai e volta no mesmo dia, como é o caso de Maragogi.

A análise dessas falas confirma de alguma forma que as relações da sociedade com a natureza têm grande influência na produção do espaço, como entendido por Lefebvre (1992) e Harvey (1989). Por exemplo, em Maceió grupos dominantes ligados à atividade imobiliária e proprietários de terrenos situados na parte norte da orla marítima de Maceió dominam ou influenciam o aparato político-institucional no interior do qual as políticas de turismo de âmbito local são formuladas. Como consequência dessa capacidade de exercer o poder, esses grupos veem direcionando a territorialização do turismo nesse destino majoritariamente ao longo da orla marítima da capital alagoana.

De maneira semelhante, esse fenômeno confirma a profunda imbricação entre as instâncias econômica, cultural-ideológica e político-institucional, identificadas por Santos (2008) com referência ao espaço geográfico, ou seja, a configuração do território é amplamente influenciada por um sistema de ações que determina onde os fixos serão implantados e como se darão os fluxos, neste caso, em torno da turistificação de Maceió. É essa lógica que está na base da turistificação do destino Maceió, no qual grupos que dominam as arenas nas quais as decisões são tomadas direcionam a territorialização do turismo nesse destino, somando-se a isso a dimensão simbólica que Haesbaert (2012) identifica como tendo um papel na configuração do território - nesse caso, a representação simbólica do sol e mar no destino Maceió. Em parte por causa desse domínio simbólico do sol e mar (natureza), o patrimônio histórico-cultural ligado a grupos sociais com pouco poder econômico e político tenha ficado à margem no processo de turistificação de Maceió.

A territorialização do turismo receptivo em Maceió e nas áreas sob a sua influência inclui apenas marginalmente outras práticas turísticas que não seja o turismo de sol e mar. Persiste localmente uma continuada invisibilidade dos recursos histórico-culturais que poderiam ser usados para se criar experiências complementares aos atrativos de sol e mar, com benefícios para a experiência do turista e para as perspectivas de sustentabilidade do destino. Sobre essa questão, a fala de um dos entrevistados é ilustrativa:

Existe uma necessidade de uma especialização e diferenciação em termos de serviço. O que acontece é que eu tive contato com alguns operadores, alguns profissionais do setor privado, na tentativa de conhecer outros segmentos, mas ao conversar com eles, eles dizem que é muito bom, mas muito demorado, é preciso muita dedicação. 
Esse tipo de atitude dos responsáveis pela oferta turística sugere a existência de uma rede de conveniências e agenciamentos presentes no seio do poder decisório acerca do turismo no destino Maceió, que reforça a organização do território turístico dirigido por interesses associados aos grupos que privilegiam a oferta de sol e mar. O trabalho de Rangel (2010) já havia identificado que o trade turístico tem indicado seus representantes para atuarem no setor público, vinculados aos órgãos oficiais de turismo do Estado de Alagoas e do município de Maceió, fenômeno que foi mencionado por um entrevistado:

A participação do setor privado na indicação desses próprios gestores tem conseguido, [...] há mais de uma década [...] indicar aos gestores maiores, governadores, prefeitos e gestores da pasta. Há uma tendência que esses gestores atuem em consonância com os interesses, não em sua totalidade, mas parcialmente, os interesses do setor privado.

A fala do entrevistado acima parece confirmar a presença de questões de poder no interior das arenas político-institucionais nas quais as políticas públicas de turismo do destino Maceió são criadas, com representantes de grupos que dominam politicamente o processo de formulação de política prevalecendo, em detrimento de setores marginais no que tange ao poder.

Apesar de ter trazido benefícios para o crescimento do destino, o qual continua em um processo de rejuvenescimento com base no turismo de sol e mar, o atual modus operandi tem perpetuado o turismo de sol e mar, como aponta abaixo a continuidade da fala do entrevistado acima. Constatou-se, em algumas entrevistas, ainda que pontualmente, certa dose de crítica à excessiva priorização do segmento de sol e mar no destino Maceió, enquanto também aborda a questão, da cultura empresarial local:

O gestor via de regra [...] tende a remar com a maré. Então está alinhado aos interesses do setor privado dos interesses políticos relacionados ao setor privado [...]. Eu enxergo, acima de tudo, uma cultura empresarial entendendo que [...] nesse momento do turismo de Maceió-Alagoas, o setor privado ocupa um espaço de destaque, não acho que isso vá mudar tão cedo, me refiro a uma independência do poder público do poder privado ao ponto de não necessariamente haver uma aliança direta, uma aliança direta me refiro a uma indicação do gestor por parte do Governador, pelo Prefeito, e ele pode não atender aos interesses do privado.

Eu entendo que essa cultura empresarial precisa ser adaptada não que a gente precise esquecer o sol e praia, mas eu acho que pra ela ser mudada, nós precisamos de alguns casos de sucesso, nós precisamos que de alguma forma, de uma rede paralela, isso normalmente envolve empresários com visões mais arrojadas, empresários dispostos a investir no médio e longo prazo que são coisas de agora. Muitas vezes pequenos empresários. [...] E recursos a esses segmentos diferenciais e com resultado começando a funcionar e de repente um rol de operadores diferenciados começar a vir trabalhar, a coisa começa a obter um fluxo natural e a gente consegue ter diversidade.

A região na qual Maceió se situa é portadora de diversificados recursos naturais como, por exemplo, praias, campos de dunas, restingas, duas lagunas, sendo uma com $18 \mathrm{~km}^{2}$ (Mundaú) e a outra (Manguaba) com $32 \mathrm{~km}^{2}$, canais estuarino-lagunares e mangues. Além disso, essa região detém rico acervo histórico e cultural, incluindo a história política datando do período colonial, a existência de sambaquis, diversificadas formas do saber fazer tradicional associado à pesca e à coleta de moluscos, e o artesanato. Assim, a problemática que se constata é justamente a prevalência de um tipo de exploração turística que tem dominado historicamente nesse destino, ou seja, um turismo massificado de sol e mar, em detrimento da exploração das possibilidades de diversificação da oferta do destino, com base em recursos que permitiriam aos visitantes experiências diferentes, mais ricas, e complementares. Mais uma vez, a fala de um dos entrevistados é ilustrativa da rica base de recursos que poderia alimentar uma diversificação de ofertas no âmbito do destino Maceió:

Maceió tem o litoral próprio... extenso litoral... ele não se resume à região da praia... também há a parte interna, com povoados, com culturas e identidades distintas... nós temos o alto de Ipioca... você tem comunidades tradicionais que vivem ali, de culturas distintas... você tem a região da lagoa também, com a orla lagunar muito extensa. Eu não me refiro só ao trecho que vai até o Pontal ali, e volta... refiro a Bebedouro, subindo aquilo ali no sentido Fernão Velho, de infinitas possibilidades. Se a gente se ater só à lagoa, imagine as possibilidades de trabalhar a identidade da marisqueira, do catador de sururu, do passeio de lagoa tradicional, do mangue, como isso pode ser trabalhado... a Massagueira tá aí para provar: polo gastronômico funciona muito bem e não necessariamente só turístico [...] o 
segmento histórico-cultural, a gente pode fazer esse mix aí associado também ao ecoturismo e ao turismo rural também são quatro fontes: turismo cultural, rural, gastronômico... vou dizer um quinto aqui que remonta várias propriedades na área de engenho, hotéis fazenda que envolvem a produção artesanal de rapadura, cachaça.

Assim, verifica-se a existência de atrativos que são pouco explorados, como as visitas ao histórico bairro do Pontal da Barra, o passeio a ilhas lagunares, a visita à vizinha e histórica cidade de Marechal Deodoro1, à Lagoa Manguaba ou mesmo ao bairro gastronômico da Massagueira, em comparação com os itinerários das praias marítimas, que estão no circuito das agências de receptivo local. Um dos entrevistados explica que há um

[...] subaproveitamento total, de [... ao] levarem as pessoas até lá, e só vê a lagoa sendo utilizada somente com o passeio das Nove Ilhas [...] o diferencial que poderia ser tratado principalmente quando você [tem] como carro chefe, um dos maiores, um dos mais fortes que é a questão da gastronomia. [...] quantas agências de viagens levam seus turistas para Massagueira? Nenhuma, eles não contam com o turismo de agência.

A existência de rico patrimônio histórico-cultural em Maceió, e nos lugares e municípios do seu entorno e, ao mesmo tempo, a negligência dos decisores do destino em relação a esses recursos na formatação da oferta turística de Maceió, refletem a proposição de Knafou (2001) de que os agentes do mercado, juntamente com os promotores territoriais, escolhem, delimitam, criam e inventam os lugares que serão alvo da configuração dos territórios turísticos. Nem sempre o planejamento do futuro de um destino envolve consultas abertas a todos os setores sociais e econômicos que possam estar interessados na definição da oferta turística do destino.

Mais uma vez, a fala de um entrevistado é elucidativa da existência de outras potencialidades que poderiam ser exploradas para compor a oferta do destino Maceió, como elementos de identificação cultural local, mas que não têm sido exploradas:

Então pequenas coisas... e aí vamos entrar na parte do roteiro cultural que envolve o centro da cidade associado a Bebedouro, vamos pensar na nossa identidade negra, a quebra de xangôs2 esse momento histórico que nós temos que até hoje perpetuam em momentos distintos no calendário de eventos anual da identidade afro-maceioense, afro-brasileira, a cultura do candomblé, a cultura negra, e por aí vai.

Apesar da hegemonia dos interesses dos grupos ligados à oferta de sol e mar, ocorreram algumas tentativas recentes de se agregar elementos de outra natureza, complementares à oferta de sol e mar no destino Maceió. Um exemplo é o Projeto Giro de Folguedos, que há alguns anos consiste no fomento a apresentações de folguedos típicos locais em lugares de visibilidade ou de grande movimento turístico $^{3}$. Entretanto, essas iniciativas ainda são bastante incipientes e insuficientes para uma efetiva diversificação da oferta turística do destino Maceió, com base em elementos identitários focados no seu patrimônio histórico-cultural.

Estudos internacionais como os de Cohen (1993) e Walle (1993), dentre outros, apontam que a busca pela autenticidade nos destinos turísticos pode ser efetivada através de segmentos alternativos ao turismo de massa. Ao se criar ofertas que atendem aos interesses de uma demanda com possibilidades mais amplas, destinações que historicamente têm priorizado excessivamente o segmento de sol e mar podem atrair uma maior parcela da demanda turística potencial. Assim, ao se criarem oportunidades para outras vias de valorização do turismo nos destinos, com ênfase em suas singularidades locais, geram-se alternativas à estandardização dos mercados convencionais e dominantes.

No caso de Maceió, há grande dificuldade para que iniciativas dessa natureza ganhem maior ímpeto e centralidade no processo de criação dos atrativos desse destino. Parece haver uma ênfase exagerada no curto prazo, ou seja, parece ser percebido como necessário que se ganhe dinheiro no curto prazo. Pensar o desenvolvimento do destino no longo prazo parece fora de cogitação por parte de setores locais da iniciativa privada, e, por extensão, também por parte de alguns dos dirigentes públicos dos órgãos oficiais de turismo do estado de Alagoas e do município de Maceió, afinal muitos deles foram indicados pelo trade turístico para, até certo ponto, representar os seus interesses, e não os interesses de grupos com menos poder de influenciar as decisões que, na prática, terminam por sinalizar o desenvolvimento futuro do destino. 


\section{Conclusões}

O papel do turismo de sol e mar no desenvolvimento dos destinos turísticos já foi amplamente estudado e encontra-se bem documentado na literatura, principalmente em relação aos seus impactos econômicos, sociais e ambientais. Entretanto, há menos estudos que examinam as relações entre o processo de turistificação dos destinos e a configuração do território correspondente. Este trabalho analisou como se deu o desenvolvimento do destino Maceió, Brasil, buscando explicitar como as territorializações do turismo influenciaram a construção espacial nesse destino.

O trabalho constatou que existe uma ênfase quase exclusiva no turismo de massa de sol e mar, permitida pela existência de relações estreitas entre o trade turístico e o aparato oficial municipal e estadual responsável pela formulação das políticas de turismo de Maceió, que contribuíram de forma significativa para a instalação de um processo de turistificação que privilegiou historicamente a orla marítima da cidade de Maceió, negligenciando toda uma base de recursos histórico-culturais localizada em municípios circunvizinhos, que fazem parte, geograficamente, do próprio destino. Assim, cidades históricas, a gastronomia regional, diversos tipos de artesanato e os saberes e fazeres tradicionais relacionados à pesca, têm sido praticamente deixados de lado, à medida que o turismo massificado de sol e mar migra ao longo do litoral norte de Maceió.

O processo decisório e a espacialização do turismo em Maceió fizeram com que grupos e agentes sociais de pequena representatividade econômica, ligados ao patrimônio histórico-cultural de Maceió e à economia informal, apesar de serem portadores de recursos que em tese poderiam ser de interesse para o desenvolvimento do turismo, continuem à margem do processo dominante de territorialização da atividade. Uma das consequências dessa realidade é que, ao passo em que o padrão balizado na oferta de sol e mar já passou por crises graves em Maceió, resultantes de problemas políticos, econômicos e ambientais, o destino tem sistematicamente negligenciado recursos histórico-culturais alternativos que poderiam contribuir para uma diversificação da oferta turística do destino, com o potencial de ajudar a combater eventuais crises futuras.

Portanto, o que se verifica em Maceió é a inexistência de condições favoráveis para o desenvolvimento de ações estratégicas, por parte dos planejadores e promotores territoriais do turismo, que contemplem também territorialidades alternativas àquelas do turismo de massa de sol e mar. Evidencia-se que os planejadores e gestores locais encontram-se amarrados a uma rede de conveniências mercadológicas, altamente atreladas à tipologia de sol e mar. Essa configuração territorial funciona como uma poderosa barreira à diversificação da oferta turística local, que continua a marginalizar determinados recursos e interesses periféricos, bem como outras possibilidades de criação de atrativos.

Enfim, pensamos que seja importante serem levadas em consideração três questões que poderiam contribuir para a construção de uma oferta turística mais diversificada, beneficiando não apenas os grupos econômicos e políticos ligados à oferta de sol e mar, mas também outros recursos e interesses que estão ligados a grupos sociais com menor poder econômico e político do destino Maceió, quais sejam: 1) De um ponto de vista mercadológico, o fomento a um desenvolvimento turístico atrelado a princípios de valorização também de elementos culturais singulares poderia servir como fator de captação de novas demandas, o que significaria novas possibilidades de crescimento econômico e um aumento nas territorialidades de ordem simbólica, associadas a um maior número de agentes sociais, incluindo também aqueles que se encontram atualmente marginalizados; 2) A diversificação de ofertas turísticas pode impactar positivamente o território em termos de crescimento e ampliação e diversificação nos tipos de alojamentos, opções de transportes, restauração, etc. A diversificação da oferta tem o potencial de melhorar a qualidade da experiência do visitante no destino, com benefícios potenciais também para aquele visitante que vem a Maceió motivado, predominantemente, pela busca do contato com a natureza - turismo de sol e mar; e 3) Desde que bem planejada e gerida, a inserção de elementos culturais identitários, como complemento ao turismo massificado, pode ajudar a preservar e divulgar elementos da cultura local através do tempo, atrelando-os à imagem do destino.

\section{Bibliografia}

Alagoas.

(s.d.). Secretaria de Estado do Desenvolvimento Econômico e Turismo. Indicadores turísticos de 1997 a 2015.

Brandão, M.

1937. Vade-Mecuum do turista em Alagoas. Maceió: Sergasa. 
Buhalis, D.

2000. Marketing the competitive destination of the future. Tourism Management, 21, 97-116.

Butler, R.W.

1980. The concept of a tourist area cycle of evolution: implications for management of resources. The

Canadian Geographer, v. 24, n. 1, p. 5-12.

Cohen, E.

1993. Introduction: Investigating Tourists Arts. Annals of Tourism Research. Vol. 20. P. 1-8.

Costa, F.B.

1998. Para onde vai o turismo de Maceió? Uma discussão sob a ótica da sustentabilidade. Maceió:

Programa Regional de Desenvolvimento e Meio Ambiente - PRODEMA.

Cruz, R.C.A.

2001. Introdução à geografia do turismo. São Paulo: Roca.

Cruz, R.C.A.

2000. Política de turismo e território. São Paulo: Contexto.

Duhamel P.; Knafou R.

2007. Les mondes urbains du turisme. Paris: Éditions Berlin,

Fratucci, A. C.

2008. A dimensão espacial nas políticas públicas brasileiras de turismo: as possibilidades das redes regionais de turismo. 2008. 308 f. Tese (Doutorado em Geografia), Programa de Pós-graduação em

Geografia, Universidade Federal Fluminense, Niterói-RJ.

2007. González Reverté, F.; Antón Clavé, S.

2007. Introducción. In.: González Reverté, F.; Antón Clavé, S. Orgs.). A propósito del turismo: La construcción social del espacio turístico. Barcelona, Editorial UOC.

Gunn, C.

1994. Tourism planning (3. ed.). London: Taylor and Francis.

Haesbaert, R.

S.d. Dos múltiplos territórios à multiterritorialidade. Porto Alegre, Setembro de 2004.

Haesbaert, R.

2012. O mito da desterritorialização: do "fim dos territórios" à multiterritorialidade. $7^{\circ}$ ed. Rio de Janeiro: Bertrand Brasil.

Harvey, D.

1989. The Condition of postmodernity: An enquiry into the origins of cultural change. Oxford, UK: Blackwell.

Haugland; et al.

2011. Development of Tourism Destinations. An Integrated Multilevel Perspective. Annals of Tourism Research, Vol. 38, No. 1, pp. 268-290, 201,1 Elsevier Ltd.

$\mathrm{Hu}, \mathrm{Y} .$, \& Brent Ritchie, J. R.

1993. Measuring destination attractiveness: A contextual approach. Journal of Travel Research, 32, 25-34, IBGE.

S.d. Instituto Brasileiro de Geografia e Estatística. Cidades. Disponível em: http://cidades.ibge.gov.br/ xtras/perfil.php?codmun=270430. Acesso em 16 de fevereiro de 2018.

Knafou, R.

2001. Turismo e Território: por uma abordagem científica do turismo. In: Rodrigues, A.A.B. (Org).]

Turismo e Geografia: reflexões teóricas e enfoques regionais. 3. ed. São Paulo: Hucitec. p. 62-74.

Krell, A. J.

2008. Desenvolvimento sustentável às avessas nas praias de Maceió/AL: a liberação de espigões pelo novo Código de Urbanismo e Edificações. Maceió: Edufal.

Lefebvre, $\mathrm{H}$.

1992. The production of space. Oxford: Blackwell. 2. ed.

Martins, A. A. C.

2009. O produto turístico Alagoas em seu desenvolvimento socioeconômico. Economia Política do Desenvolvimento - Revista de Ciências Econômicas da Faculdade de Economia, Administração e Contabilidade - UFAL. Maceió, v.1, n.6, set./dez. 2009. Edufal. p. 83-109.

Martins, C.G.M.S.; Lima, L.M. de

2007. Que Imagem Vende a Cidade-Mercadoria? Dois Estudos de Caso: Maceió-AL e João Pessoa-PB. Anais do XII Encontro da Associação Nacional de Pós Graduação e Pesquisa em Planejamento Urbano e Regional. Belém - Pará - Brasil). 
Murphy, P., Pritchard, M. \& Smith, B.

2000. The destination product and its impact on traveler perceptions. Tourism Management, 21, 43-52, Pearce, D.

1989. Tourist development. New York: Longman,

Rangel, M. G.

2010. Destinação Turística Maceió: ciclo de vida e perspectivas de crescimento nos próximos anos. 2010.

165 f. Dissertação (mestrado em desenvolvimento e meio ambiente: desenvolvimento sustentável.

Programa Regional de Pós-graduação em Desenvolvimento Meio Ambiente). Universidade Federal de Alagoas, Maceió.

Rodrigues, A.A.B.

1997. Turismo e espaço: rumo a um conhecimento transdisciplinar. São Paulo: Hucitec.

Rodrigues, A. A. B.

1997a. Turismo e desenvolvimento local. Editora Hucitec.

Rodrigues, A.A.B.

1999. Turismo e Geografia: reflexões teóricas e enfoques regionais. São Paulo, Hucitec.

Rodrigues, L.C.

2015. Turismo em espaços urbanos: processos de turistificação no Nordeste brasileiro e no Caribe Mexicano. Revista Iberoamericana de Turismo - RITUR, Penedo, Vol. 5, Número Especial, p. 81-104, abr. Santos, M.

2008. Metamorfoses do Espaço Habitado: fundamentos Teóricos e Metodológicos da Geografia. São Paulo: Edusp.

Urry, J.

1990. O olhar do turista: lazer e viagens nas sociedades contemporâneas. São Paulo: Sesc/Studio Nobel, Vasconcelos, D.A.L.

2005.Turistificação do Espaço e Exclusão Social: a revitalização do bairro de Jaraguá, Maceió-AL, Brasil.

Turismo em Análise - São Paulo. CRP/ECA/USP: Aleph, 1990. Vol. 16. n. 1, p. 47-67,

Veras Filho, L.

1991. História do turismo de Alagoas. Maceió: SERGASA.

Walle. A.H.

1993. Tourism and traditional people: forging equitable strategies. Journal of Travel Research, Vol. XXI, p. 137-140.

\section{Notas}

1 O município faz parte da Região Metropolitana de Maceió. A cidade foi a primeira capital de Alagoas e cidade onde nasceu o Marechal Deodoro da Fonseca, proclamador da República e primeiro presidente do Brasil. Marechal Deodoro é conhecida também por suas construções de valor histórico, igrejas, casario e outras edificações que remontam ao período colonial.

2 A Quebra de Xangô foi a destruição de terreiros ligados a religiões de matriz africana por causa de intolerância religiosa e preconceito na cidade de Maceió, capital do Estado de Alagoas, em 1 de fevereiro de 1912.

3 Projeto realizado pela Prefeitura de Maceió, por meio da Fundação Municipal de Ação Cultural - Fmac. 